institutions, whether research councils, research institutions or other bodies essential to provide the means and conditions for effective work and to formulate projects and programmes which are worth while and practicable. The evidence that establishment of an appropriate research council might be of decisive value grows, and the case presented by Profs. Glass and Gluckman should not only receive the most serious consideration by Lord Robbins and his Committee but also equally merits attention in the meanwhile by the Minister for Science and his Advisory Council.

\section{APPLICATIONS OF X-RAYS IN SCIENCE AND TECHNOLOGY}

\section{Advances in X-ray Analysis}

Proceedings of the Sixth, Seventh, Eighth and Ninth Annual Conferences on Applications of X-ray Analysis. (Sponsored by University of Denver, Denver Research Institute.) Vol. 1: Pp. 494. 75s. net. Vol. 2: Pp. 359. 75s. net. Vol. 3: Pp. viii +376. 90s. net. Vol. 4: Pp. v+568. 115s. net. (London: Sir Isaac Pitman and Sons, Ltd., 1960 and 1961.)

DROGRESS in the development of X-ray methods $P$ in physics, chemistry and technology continues at an ever-increasing rate. Responding to the challenge of this situation, the University of Denver in Colorado has, since 1951, organized a conference each summer on the applications of X-ray analysis. Starting as a very small meeting in 1951, these conferences gained so much in popularity and support that, with the advent of the sixth, in 1957, bookform publication of all the papers was decided on. The books under review contain the material presented at the Denver conferences of 1957, 1958, 1959 and 1960, respectively: about 120 papers in all.

In fact, these books comprise the first numbers of what is in effect a new journal, the title of which should perhaps be, "Applications of X-rays in Science and Technology". The papers are each complete in themselves and independent of one another. Their interest is primarily technological with the accent on metallurgical science-an understandable bias. Every paper involves X-rays; this is the only unifying theme. Otherwise their scope is very wide and varied. The word 'analysis' used in the title of the volumes covers both chemical analysis and solid-state physical investigations. X-ray emission, absorption, diffraction and fluorescence are represented; the design of instruments is extensively discussed; measurements of particle size, of film thickness, of diffusion, of phase relationships in alloys or in mineral systems are reported, together with technical engineering applications such as the measurement of steam voids in superheated water flowing through steel tubes at $1,000 \mathrm{lb} / \mathrm{in}^{2}$. The only aspect conspicuous by its infrequency is the determ. ination of molecular structure.

Volume 1 has the curious feature of the inclusion of the conference banquet speech-on Vanguard satellites! Volume 4 has the special feature of recording some of the verbal discussion following the papers; this is sometimes rather inconsequent (Dr. X: "Do you form a carbon film in there at all ?") and would be better omitted, but it does add a human touch. Volumes 3 and 4 include the contribu- tions of invited European scientists. All four volumes are comparatively well produced, though misprints are not uncommon; plates are of poor quality, but diagrams are clear.

One disadvantage of this sort of production of conference papers is that it can, and sometimes does, duplicate existing publications: that is, there is nothing to prevent papers appearing twice over. Further, the expense of these volumes is high, presumably owing to their limited distribution. Nevertheless, we may congratulate the University of Denver on these annual conferences and wish them continuing success.

J. H. ROBERTSON

\section{MANPOWER AND MATERIALS}

\section{Organization, Automation and Society}

The Scientific Revolution in Industry. By Robert A. Brady. (Publications of the Institute of Business and Economic Research, University of California.) Pp. xiv +481. (Berkeley and Los Angeles: Univer. sity of California Press; London: Cambridge University Press, 1961.) 8.50 dollars; 68s. net.

II

HIS book is an economist's assessment of the need to rationalize the economic structure of our industrial society. The theme is the maximizing of production combined with conservation of resources, by large-scale economic planning.

The author, who is emeritus professor of economics in the University of California, writes vividly on the impact of the "second industrial revolution" and suggests that because of the part played by science and scientists in bringing it about it should be looked on as "the scientific revolution in industry".

The book is a stimulating one, and it must be agreed that much more wide-scale planning or "rethinking through", as Brady frequently puts it, is urgently needed in the field of industrial economics. This book contributes to this by assembling a considerable quantity of economic facts and suppositions, particularly on the supply of raw materials, electricity production, standards formulation, retail distribution of goods and telecommunications. References are made to books, articles and pamphlets from both American and European academic, industrial, magazines and Government sources. Regrettably, no reference is later than 1956. Further, the references are immersed in 634 annotated notes covering 40 pages immediately following the 424 pages of the thirteen chapters, and there is no separate bibliography.

Prof. Brady admits that to achieve the necessary high order of industrial organization there must be a world-wide system of standards of form and dimension of products, that many services such as transport and telecommunications will have to be internationalized and that the large manufacturing companies will have to at least submit to a centralized internationally controlled planning organization. The idealism is refreshing but regrettably unrealistic.

The words 'science' and 'scientific' are used very loosely throughout the book, usually to flatter rather than define. The thinking that has gone into the book is clearly far-reaching and far-sighted, but it is to be $\mathbf{r e g r e t t e d}$ that the 'scientific' solutions that are suggested do not include any controlled investigations into the effectiveness of these or alternative solutions, nor are there suggested any social criteria for evaluating the proposals, the sole criterion being 